\title{
Improving access to long-term contraceptives in rural Guatemala through the Ministry of Health
}

\author{
Edwin Montufar \\ Carlos Morales \\ Ricardo Vernon \\ Population Council \\ Carlos Brambila \\ Population Council \\ Jorge Solorzano \\ Population Council
}

Follow this and additional works at: https://knowledgecommons.popcouncil.org/departments_sbsr-rh

Part of the Demography, Population, and Ecology Commons, International Public Health Commons, Maternal and Child Health Commons, and the Public Health Education and Promotion Commons How does access to this work benefit you? Let us know!

\section{Recommended Citation}

Montufar, Edwin, Carlos Morales, Ricardo Vernon, Carlos Brambila, and Jorge Solorzano. 2005. "Improving access to long-term contraceptives in rural Guatemala through the Ministry of Health," FRONTIERS Final Report. Washington, DC: Population Council. 


\title{
Improving Access to Long-Term Contraceptives in Rural Guatemala through the Ministry of Health
}

\author{
Edwin Montufar, Carlos Morales APROVIME \\ Ricardo Vernon, Carlos Brambila, Jorge Solórzano \\ FRONTIERS, Population Council
}

August 2005

This study was funded by the U.S. AGENCY FOR INTERNATIONAL

DEVELOPMENT (USAID) under the terms of Cooperative Agreement Number HRNA-00-98-00012-00 and Subagreement number AI03.04A. The opinions expressed herein are those of the author and do not necessarily reflect the views of USAID. 


\section{SUMMARY}

The purpose of this study was to test a model to train nurse auxiliaries at health centers and posts in Guatemala and to determine whether these providers could deliver adequate, cost-effective services. The training model consisted of: a) selection of nurse auxiliaries; b) two-day group training; c) on-the-job training, including work with actual clients at the trainees' work centers; and d) certification of trainees that had conducted at least five quality insertions under supervision. Clinical job-aids and promotional materials were developed to assist training.

The project consisted of two 12-month phases. In the first phase, 45 of 52 enrolled health providers completed training and delivered 301 IUD services, whereas in the second phase, 45 of 114 enrolled providers completed training and delivered 424 IUD services. As a result, there was an increase in the overall number of IUD services provided by participating health centers and posts, as well as in the couple-years of protection provided by IUDs.

Other results showed that a large proportion of IUD acceptors had never used a method or had just given birth. The quality of services provided by trainees improved over time. The total cost of the strategy was about US $\$ 402$ per certified service provider, $\$ 50$ per IUD service delivered, or $\$ 14.28$ per couple-year of protection. The main recommendation derived from the project is to scale up the strategy nationally. 


\section{CONTENTS}

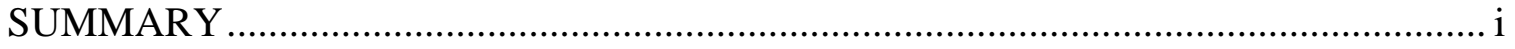

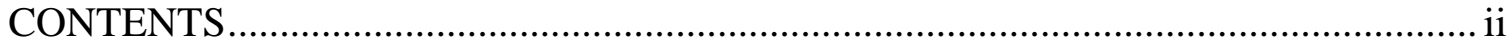

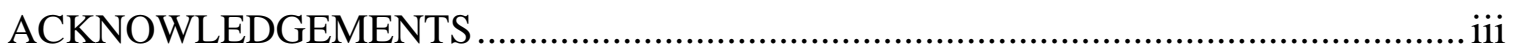

I. INTRODUCTION: THE IUD IN GUATEMALA …………………....................... 1

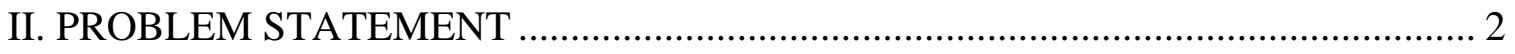

III. POTENTIAL SOLUTION ................................................................................ 2

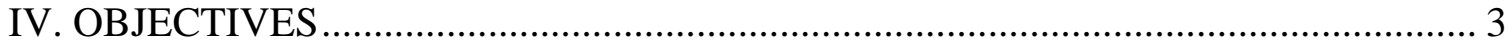

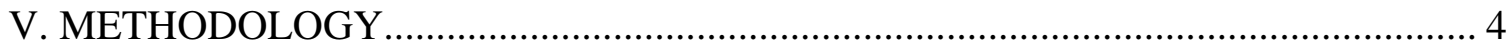

5.1 Study Design ........................................................................................................ 4

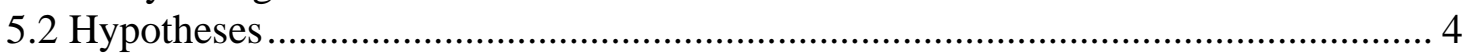

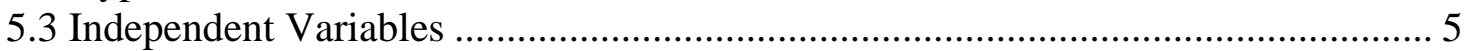

5.4 Dependent Variables and Information Sources ....................................................... 5

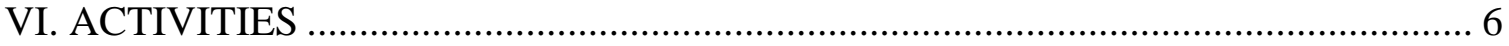

6.1 Identification, Development, and Adaptation of Clinical, Training and IEC

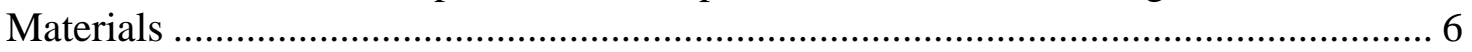

6.2 Selection of Intervention Sites ................................................................................. 7

6.3 Training and Certification of Nurse Auxiliaries ...................................................... 9

6.4 Project Coordination and Supervision ................................................................ 14

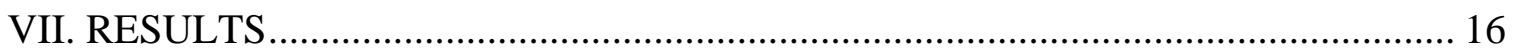

7.1 Number of IUD Services Provided during Training............................................... 16

7.2 Screening and Contraindications .......................................................................... 18

7.3 Follow-up, Failure and Complication Rates ........................................................... 19

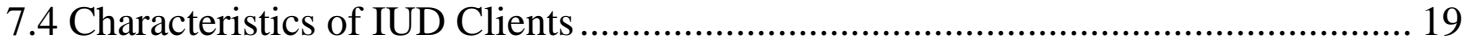

7.5 Impact on IUD Service Provision ........................................................................... 20

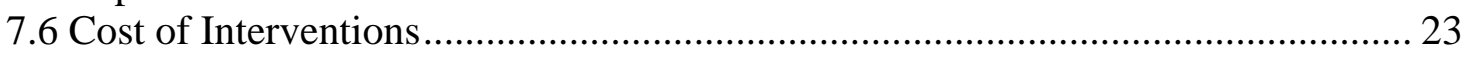

VIII. DISSEMINATION AND USE OF RESULTS.................................................. 26

IX. CONCLUSIONS AND RECOMMENDATIONS .................................................... 28 


\section{ACKNOWLEDGEMENTS}

We would like to acknowledge and thank the following persons for their invaluable contributions: Dr. Alejandro Silva and Dr. Carolina Rivas of the National Reproductive Health Program of the Ministry of Health (MOH); Dr. Benedicto Vasquez and Dr. Carlos Morales, of the Executing Unit of Agreement No. 520-0428 between USAID and the $\mathrm{MOH}$; the health area and district directors, as well as the chief nurses that participated in the project; and especially, the professional nurses and nurse auxiliaries that coordinated and provided family planning services in participating health centers and posts in Chiquimula, Chimaltenango, Escuintla, El Progreso, Jalapa, Jutiapa, Santa Rosa, Suchitepequez, and Sololá.

Moreover, we would like to mention our deepest appreciation to our colleagues at the Calidad en Salud Project (implemented by a consortium lead by the University Research Corporation, with the participation of JHPIEGO, EngenderHealth, Population Council and Population Communication Services) and the Maternal and Neonatal Health Project (implemented by JHPIEGO), for their unfailing and enthusiastic support of project activities, their donation of IEC and clinical materials, and their sound technical advise. 


\section{INTRODUCTION: THE IUD IN GUATEMALA}

According to the 2002 Census, Guatemala has 11.2 million inhabitants, of whom 54\% live in rural areas — defined as towns with less than 2,500 inhabitants. The country's annual population growth is $2.6 \%$, with a total fertility rate of 4.4 children per woman. Of the total population of the country, six million live below the poverty line, a situation that is worse in rural areas. The birth rate is 36.6 per 1,000 inhabitants and the illiteracy rate is nearly $30 \%$ among those aged $15-59$ years (about two thirds of whom are women). The mortality rate is 7.4 per 1,000 population and life expectancy is under 65 years, one of the lowest in the region. Guatemala ranks among the countries in the Americas with the poorest health and socio-economic indicators and has proportionally the largest indigenous population in the continent. ${ }^{1}$

The 2002 Maternal and Child Health Survey ${ }^{2}$ showed that $43 \%$ of married women in fertile age (MWFA) use a contraceptive method, $34 \%$ of whom use a modern method. Among these users, the most popular methods are female sterilization (17.8\%), injectables $(9.0 \%)$, oral contraceptives (3.4\%), and condoms (2.3\%). Only $1.9 \%$ of women living in union use IUDs, a smaller figure than that recorded in $1999(2.2 \%)$ and in 1995 (2.8\%). More women in urban areas (3.4\%) use IUDs compared to women in rural areas (0.9\%); more non-indigenous use IUDs (2.4\%) than indigenous women $(0.4 \%)$; and more women with high school or higher education (5.2\%) use IUDs than women with elementary education (1.4\%) or without formal schooling $(0.4 \%)$. Therefore, the IUD is used by a population group that has greater access to services and a comparatively higher socioeconomic level.

In Guatemala, the main providers of IUD services are APROFAM (35.9\%), the Instituto Guatemalteco de Seguridad Social (IGSS) (23\%), and private physicians, clinics and hospitals. Only 5.9\% of IUD users said that they obtained the method at the Ministry of Health $(\mathrm{MOH})$ hospitals, centers, and posts. In contrast, more than $29 \%$ of female sterilization users said they had received the method at a public hospital. Considering the size of the $\mathrm{MOH}$ clinical infrastructure (34 maternity hospitals, over 250 health centers with physicians and professional nurses, and more than 800 health posts that offer referral services), the $\mathrm{MOH}$ should provide more IUD services in the country, especially in view of the large unmet need for methods. In 2002, unmet demand for contraception was $27.6 \%$ among MWFA of whom 12.5\% had an unmet need for limiting future births. In rural areas, unmet need for contraceptive methods was estimated at $32 \%$, and among indigenous women, nearly $40 \%$.

The IUD has several advantages: it is highly effective, provides protection for at least 10 years, is immediately reversible, can be used during lactation and menopause, does not produce adverse reactions when used in combination with medication, and has very few

\footnotetext{
${ }^{1}$ Interestingly, although $41 \%$ said to belong to an indigenous group, only $31 \%$ were native speakers of an indigenous language. About $68 \%$ of the indigenous population lives in rural areas.

${ }^{2}$ Ministerio de Salud Pública y Asistencia Social (MSPAS) et al. 2003. Guatemala. Encuesta Nacional de Salud Materno Infantil 2002. Guatemala, Guatemala, October
} 
side effects. ${ }^{3}$ Of temporary methods, the IUD is the most cost-effective method (in terms of money spent per unit time of protection) if used for two years or more ${ }^{4}$. The device costs the provider about US\$2.00, and it can be inserted by trained personnel at nearly any health center. Since IUD users do not need to be resupplied, they do not incur client costs related to additional clinic visits.

\section{PROBLEM STATEMENT}

If the IUD offers so many comparative advantages for women in countries such as Guatemala, why is it not more widely used? Various studies ${ }^{5}$ have shown that in 2002 about half of the health centers did not have the equipment and trained personnel needed to provide IUD services. Moreover, many of the trained physicians and professional nurses did not provide IUD services due to their heavy workload (they provide all curative services) and because the services are perceived as too time consuming or too burdensome. Perhaps for these reasons, less than $40 \%$ of the providers discuss the IUD during family planning counseling and talks. Lack of appropriate training was also noted among the many providers that had misconceptions about the method. As for potential users, less than 54\% of the women had heard about the method (the IUD ranks among the least known methods in Guatemala); those who had, however, mentioned only few of its characteristics and believed the many rumors that surround it. Few knew that the $\mathrm{MOH}$ offered IUD services and identified APROFAM, the IGSS, and other service providers as the sole providers of this — in their opinion — unaffordable method.

\section{POTENTIAL SOLUTION}

What can the Guatemalan Ministry of Health do to increase access of the poorest and neediest women to the IUD? The diagnostic studies reviewed in the previous section show that the $\mathrm{MOH}$ should increase the availability of equipment and supplies, and should expand the base of providers trained to provide IUD services, preferably nurse

\footnotetext{
${ }^{3}$ Hatcher, Robert; W. Rinehart, R. Blackburn and J.S. Geller. 1997. The Essentials of Contraceptive Technology. Population Information Program, Center for Communication Programs, The Johns Hopkins School of Public Health. July

${ }^{4}$ Chiou CF, Trussell J, Reyes E et al. Economic analysis of contraceptives for women. Contraception 2003;68:3-10.

${ }^{5}$ (1) A multicenter diagnostic study of post-obstetric event services conducted at 17 hospitals (Brambila, Carlos; Werner Figueroa, and Berta Taracema. 2001. Situational analysis of post-obstetric event services in public hospitals in Guatemala. Diagnostic study Final Report. The Population Council, Guatemala, September); (2) a diagnostic study of IUD service supply and demand (Brambila, Carlos and Berta Taracena. 2002. Availability and acceptability of IUDs in Guatemala. Operations Research Final Report. The Population Council, Guatemala, September.); and (3) an operations research study on the quality of counseling provided to women at Ministry of Health centers and posts (León, Federico; Carlos Brambila, Marisela de la Cruz, John Bratt, Julio García Colindres, Benedicto Vásquez, and Carlos Morales. 2002. Improving Provider-Client Interactions at Guatemalan MOH Clinics: Extent and Cost. Operations research Final Report. Frontiers in Reproductive Health, the Population Council, January)
} 
auxiliaries $^{6}$, who were implicitly authorized to provide these services in the National Service Delivery Guidelines published in 2000. Other studies in Central America ${ }^{7}$ have shown that nurse auxiliaries can provide IUD services safely and effectively, and that they are often more motivated than physicians and professional nurses. Training in Guatemala, however, can be complicated for several reasons. First, there are few service delivery sites with a large enough volume of IUD services to allow trainees to obtain minimum practical experience with clients. Second, although service delivery norms do not preclude nurse auxiliaries from inserting or removing IUDs, many physicians and professional nurses do not regard them as IUD service providers. Third, the IUD is little known in Guatemala, and thus the demand for the method at health centers and posts is likely to be poor.

The network of MOH primary care facilities comprises 254 health centers staffed with a physician and a professional nurse, located in cities with more than 5,000 inhabitants, and 857 health posts staffed with a nurse assistant and a rural health technician ${ }^{8}$, located in towns of 2,000 to 5,000 inhabitants. If nurse auxiliaries could be trained using a model that is affordable, the $\mathrm{MOH}$ would greatly expand IUD availability at sites with the highest unmet need for long-term methods. Even at health centers that have trained physicians and nurses, training nurse auxiliaries could greatly improve the availability of the method, because the workload of physicians and nurses often prevents them from offering the method to potential users.

\section{OBJECTIVES}

The main objective of this project was to test a strategy to train and certify nurse auxiliaries and professional nurses in IUD service provision at health centers and posts in Guatemala.

The specific objectives were:

- Test a model to train and certify nurse auxiliaries and other providers in IUD service delivery at health centers and posts. The model consisted of two phases: 1) 12-hour theoretical training (that included counseling, use of checklists to rule out pregnancy, practical training in insertion and removal using pelvic models, and detection of infection, perforation, and expulsion); and 2) supervised follow-up practical training

\footnotetext{
${ }^{6}$ Nurse auxiliaries are health providers that have completed at least primary school (six years) and one year of training as nurse auxiliaries.

${ }^{7}$ See, for example, Villanueva, Yanira; L. Hernández, I. Mendoza y R. Lundgren. 1998. Expansión del Rol del Personal Auxiliar de Enfermería en la Prestación de Servicios de Planificación Familiar y Toma de Citología. Informe final de investigación operativa. Population Council, INOPAL III, Tegucigalpa, Honduras; y Villanueva, Yanira; I. Mendoza, C. Aguilar, S. Rodríguez y R. Vernon. 2001. Expansión del rol de la auxiliar de enfermeria en la prestación de servicios de salud reproductiva en Honduras: Fase 2. Informe final de investigación operativa. Population Council, Fronteras de la Salud Reproductiva, Tegucigalpa, Honduras.

${ }^{8}$ Ministerio de Salud Publica y Asistencia Social, Unidad de Información. 1995. Red de Establecimientos del Ministerio de Salud Pública y Asistencia Social. Guatemala, Guatemala. Mayo.
} 
in counseling, use of checklists to rule out pregnancy, insertion and removal using pelvic models, and IUD insertion and removal with clients at hospitals, health centers and/or health posts. Each trainee conducted at least five insertions under direct supervision of qualified medical personnel, who assessed their competence by means of a checklist. To be certified, providers needed to demonstrate their competence and complete a minimum of five insertions in actual clients.

- Determine the number of women who request an IUD but do not receive one, and the reasons for not receiving it.

- Calculate the costs of implementing the model on a large scale.

\section{METHODOLOGY}

\subsection{Study Design}

This demonstration project used a non-experimental design with one final measurement. The project consisted of two phases: one from January to November 2003, and the other from January to November 2004. Different health districts participated in each phase ${ }^{9}$. In the first phase, we worked in 26 health districts in three health areas, Escuintla, Suchitepequez, and Chiquimula; and tested the model in health centers and posts. In the second phase, activities were conducted only at health centers in 42 districts of six health areas: Chimaltenango, Jalapa, Jutiapa, Progreso, Santa Rosa, and Sololá. Activities were restricted to health centers on request of health officials of the new administration (inaugurated in January 2004) because they thought it safer to provide the services at sites where direct medical supervision was available. This report will refer to each project phase separately.

\subsection{Hypotheses}

1. Most nurse auxiliaries will learn to provide high quality IUD services as determined by direct observation of supervisors using a checklist.

2. Of the trained nurse auxiliaries, many will complete the certification process, which includes five supervised IUD insertions with clients.

\footnotetext{
${ }^{9} \mathrm{MOH}$ services are geographically organized in health areas, with each health area usually covering an entire Department (the equivalent of an American state). Health areas are divided into health districts. Each health district counts at least one health center (staffed with at least a physician, a professional nurse, and a nurse auxiliary) and 1 to 12 (four or five on average) health posts (staffed with a nurse auxiliary and sometimes a rural health technician). Health center staff supervises health posts.
} 


\subsection{Independent Variables}

For this project, the independent variable was the IUD training and certification model for nurse auxiliaries. The model consisted of:

- Selecting nurse auxiliaries. The selection criteria included having worked for at least a year at a participating facility, endorsement from the district physician and chief nurse, proven manual dexterity, interest in family planning, and willingness to receive IUD training. These criteria were established based on the experiences of similar projects in Latin America ${ }^{10}$.

- Two-day theoretical group training. Topics included in this training were contraceptive counseling, techniques for IUD insertion and removal, use of a checklist to determine user eligibility, infection prevention techniques, prevention of perforation and expulsion, review of the aseptic insertion technique by practicing IUD insertion and removal using pelvic models.

- Identifying IUD service demand. Trainees were to inform community members about the new availability of the IUD at the health center or post and to identify women interested in receiving the method. This training component was crucial, because without demand, the nurse auxiliaries would be likely to lose their newly acquired skills.

- Conducting at least five supervised insertions or removals in the trainees' districts. Having identified women interested in using an IUD, trainees were to conduct insertions under the supervision of a project instructor. In the first phase, most of the insertions were to be conducted at the trainees' service delivery facilities; up to three supervision visits were scheduled for each facility. For the second stage, insertions would take place at the trainees' health centers or, as an exception, at any other health facility in the area.

- Certifying trainees. Trainees who completed training would receive a diploma certifying them as skilled IUD service providers.

\subsection{Dependent Variables and Information Sources}

The dependent variables defined for this study were: 1) number of trainees enrolled and certified; 2) number of insertions conducted per trainee; 3) degree of compliance with established IUD insertion and removal procedures (as determined by supervised insertions during community sessions); 4) number of service refusals and reasons for refusal; and 5) complications observed during the one-month follow-up period.

\footnotetext{
${ }^{10}$ See Villanueva, et al, 2001, op. cit.
} 
Information was collected from clinical records and service statistics, without individual identifiers to protect the confidentiality of the women.

\section{ACTIVITIES}

\subsection{Identification, Development, and Adapting of Clinical, Training and IEC Materials}

The following training and IEC materials were developed as part of this project. In the second phase, we often used improved versions of the first phase materials. The improved versions built on the experiences of the trainees and of colleagues that attended an OR workshop on the IUD in Southampton, England, in February 2004. In most cases, this report presents the improved versions.

- Clinical job-aids. These included: a) an eligibility checklist to help providers assess IUD contraindications; b) a checklist to rule out pregnancy (a more conservative version of the checklist produced by Stanbach et al); c) an observation checklist to assess counseling and IUD insertion and removal skills (this checklist includes step-by-step actions to provide high quality IUD services, and was used by supervisors to certify trainees); and d) posters to reinforce training (two posters with photographs illustrating step-by-step IUD insertion and removal procedures were designed and printed in August 2003 and were distributed to all project participants). The posters were an excellent training aid and a reminder of the basic steps for providers. In 2004, FHI reprinted these posters in letter-size format for use in Nicaragua, and copies were also made for Honduras.

- IUD Service Delivery Training Manual. ${ }^{11}$ A copy of this manual was given to supervisors, instructors, and trainees. It was adapted from manuals produced by JHPIEGO and FHI, contraception manuals, the Official MOH Service Delivery Guidelines, and other previous IUD manuals and guidelines. ${ }^{12}$ The manual discusses the basics of IUD service provision, myths and rumors about the IUD, counseling for an informed choice, steps to rule out pregnancy, basic IUD information, contraindications, insertion and removal techniques (including infection prevention procedures), and IUD client follow-up. The manual also incorporates all the aforementioned job-aids and the WHO eligibility checklist for IUD services. The manual, extensively reviewed by Guatemalan experts, was

\footnotetext{
11 Montufar, Edwin; C. Brambila and G. Ortega. 2003. Manual de Capacitación en Inserción de DIU. Guatemala, Population Council, October.

12 JHPIEGO (1992). IUD Course Handbook Guide for Participants. Baltimore, Maryland, November, 61 p.; FHI. 2000. Series de Actualización en Tecnología anticonceptiva. Información General. FHI; Hatchett, Robert A.; W. Rinehart, R. Blackburn, J.S. Séller. 1997. The essentials of contraceptive technology. Population Information Program, Center for Communication Programs, The John Hopkins School of Public Health, July; Ministerio de Salud Pública. 2003. Guías Nacionales de Salud Reproductiva. Tomo I. Planificación Familiar. Ministerio de Salud Pública, Guatemala, Guatemala.
} 
adopted by the $\mathrm{MOH}$ as its official training handbook. In February 2004, Amelia Kaupfman (URC) assessed the manual from a pedagogic perspective and concluded that it focused on provider behavior change and performance improvement. Consequently, the Calidad en Salud Project adopted the manual for its training activities, thus ensuring its continued use in the next five years.

- Brochures, posters, and leaflets. Calidad en Salud donated to the project 35,000 brochures on all methods and 30,000 brochures on the IUD. In addition, we designed and produced 100,000 copies of a leaflet in half-letter-size format that listed the main advantages of the IUD, and 2,000 copies of a letter-sized poster that provided information similar to that on the leaflet. Focus groups were conducted with the target population to determine what advantages were more important and to pretest the images and texts.

- Manual for information activities. A manual was produced to explain how to implement a strategy to inform community members about the IUD. ${ }^{13}$ The manual recommends providing IUD information to all clients and asking them to distribute leaflets among friends and neighbors that might be interested in the method. Other recommendations are giving talks to clients and community members, including a two-minute message on the new availability of the method; handing out a leaflet or brochure to those that might be interested in the method; placing posters throughout the community; and organizing and conducting special one-day events (called jornadas in Spanish) on the IUD and other health topics.

\subsection{Selection of Intervention Sites}

In the first phase, officers of the MOH National Reproductive Health Program proposed the Chiquimula, Escuintla, and Suchitepequez health areas as study sites, because the $\mathrm{MOH}$ had designated them as pilot areas to test innovative strategies to then scale them up nationally. In this phase, we tested our strategy at health centers and posts. Although we had proposed to randomly select three health districts in each area and a health center and two health posts in each district, among those that met the inclusion criteria, in Escuintla and Suchitepequez area chiefs insisted that training be provided in all districts in the health area. In Chiquimula, area chiefs felt that since nurse auxiliaries at health posts lacked adequate supervision from physicians, they could not provide the services. Thus, in this first phase, 26 districts (health centers) and 9 health posts participated in the project.

For the second phase, Jalapa, Jutiapa, El Progreso, and Santa Rosa were the selected health areas, and on request of the $\mathrm{MOH}$, the strategy was expanded to Chimaltenango and Sololá. These areas had received few IUD services in previous years and were in need of reinforcement. Thus, a diagnostic study was conducted and those districts that met inclusion criteria and were interested in having their staff trained were invited to participate. The inclusion criteria were endorsement from the district physician and chief

${ }^{13}$ Ministry of Health, APROVIME and FRONTIERS in Reproductive Health, Population Council. 2004. Estrategias para ampliar el acceso a la T de Cobre (DIU). Guatemala, June. 
nurse, one year of service at their present worksite, proven manual dexterity (as determined by their experience attending births, obtaining Pap smears, and suturing), a positive attitude toward family planning, and interest in receiving training. A total of 42 health centers accepted the invitation.

Table 1 shows the total number of health centers (i.e., districts) and health posts in each participating health area and the number that participated in the project.

Table 1. Total number of participating health centers and health posts, by project phase and health area

\begin{tabular}{|l|c|c|}
\hline Health Area & $\begin{array}{c}\text { Participating Health } \\
\text { Districts (Health Centers) }\end{array}$ & $\begin{array}{c}\text { Participating } \\
\text { Health Posts }\end{array}$ \\
\hline First Phase (2003) & 4 & 0 \\
\hline Chiquimula & 12 & 2 \\
\hline Escuintla & 10 & 7 \\
\hline Suchitepequez & 26 & 9 \\
\hline Subtotal & 7 & \\
\hline Second Phase (2004) & 6 & \\
\hline Chimaltenango & 5 & \\
\hline Jalapa & 7 & \\
\hline Jutiapa & 12 & \\
\hline El Progreso & 5 & \\
\hline Santa Rosa & 42 & \\
\hline Solola & 68 & \\
\hline Subtotal & & \\
\hline Total & & \\
\hline
\end{tabular}

The diagnostic study conducted in the second phase showed that all 34 health centers visited had electricity, drinking water, and sanitary services. All but one had IUD instruments, including insertion kits, speculum, ring pliers, tenaculum, histerometer, scissors, and stainless glass. All but two or three had basic supplies such as cotton, gloves, and a sheet to cover the patient. Half of the centers used sterilization or high-level disinfectants (such as Hibitane), and the remaining half used disinfecting solutions such as Formulex, Clorhexidine, Sablon, and chlorine. At $85 \%$ of the centers, providers had clear and correct guidelines to prepare the solutions. All health centers had guidelines and supplies for solid waste disposal. As many as 25 health centers had brochures on all contraceptive methods, but only one or two had posters, leaflets, and other clinical jobaids. The level of visual or auditory privacy was somewhat inadequate at three of the 34 health centers, and recommendations were given to correct the problem. 


\subsection{Training and Certification of Nurse Auxiliaries}

\section{Two-day group training}

Training was conducted in two phases. The first phase consisted of a two-day in-class program for all the trainees in a health area. Topics included in the theoretical training were counseling, IUD insertion and removal techniques, a review of project clinical jobaids, infection prevention techniques, and adequate preparation of different concentration solutions. Theoretical training also examined how to determine infection, perforation and expulsion, reviewed the aseptic insertion technique by practicing insertions and removals on pelvic models, and discussed case studies to reinforce certain topics in case management. During the first day of training, the nurse auxiliaries' counseling and insertion and removal skills were evaluated. Several of these topics were reinforced by means of a peer-supported system by which pairs of trainees were to observe each other while conducting a particular procedure and then give supportive feedback. On the second day, a three-hour session discussed strategies to identify demand for IUD services in the communities, as well as the use of the project IEC materials. We advised participants to begin IEC activities as soon as they had returned to their communities, since practical training would be contingent upon their finding clients interested in receiving the method. The trainers were the principal investigator and two supervisors of the National Reproductive Health Program.

The two-day training sessions took place in March, April, and May 2003, and in April, May, June, August, and September 2004. The beginning of activities of the second phase was delayed by the inauguration of the new president in January 2004, and by the ensuing changes of health officials at all MOH levels. Further, because of the new administration, even those officials who had already been appointed were reluctant to make any decisions to continue project activities agreed with former health authorities.

We had originally proposed to train only nurse auxiliaries, but since during our first visits to health centers we noted that many professional nurses and even physicians who were to supervise the trainees had not been trained or had lost their skills due to lack of use, we decided to train these providers as well. The project had initially proposed to include three districts of each area in the first phase, but area chiefs in Escuintla and Suchitepequez insisted that training be provided in all health areas. Similarly, although we had proposed to include health posts of each district in the first phase, the Escuintla area chief thought that health post nurse auxiliaries did not have the appropriate medical supervision to provide IUD services and thus decided not to include this type of facilities in the project.

Workshops were evaluated using pre- and post-training tests. Nurses increased their test scores from 68 to 85 points on average, whereas nurse auxiliaries increased their scores from 65 to 80 points on average, based on a 100-point scale. The pre-training test showed that trainees had scarce knowledge about infection prevention, user eligibility criteria, high-level disinfection procedures, and insertion and removal techniques; post-training scores on these topics, however, were the highest. 


\section{Activities to identify demand}

Upon returning to their service delivery sites, providers began to inform their clients that the IUD was now available at the health facility, and asked them to distribute leaflets among neighbors and friends who might be interested in the method. They also gave talks on the method in the community, and asked their volunteer health agents to mention the new availability of the method at the end of their talks and to display posters in public places. Whenever a woman showed interest, she would receive a brochure on the IUD, and if she requested information at the health center or post, she was given counseling about all contraceptive methods. Those still interested in the IUD after counseling were given an appointment for a future date, when one of the project trainers would visit the trainee.

In regards to marketing the new IUD services, trainees conducted information activities in addition to those that had been recommended in the two-day training. In Chiquimula and Esquipulas, they asked local radio stations to make brief announcements about the new availability of the method at the health centers. Several districts used vehicles with loudspeakers to inform their communities, and the IUD services were advertised at yearly health fairs - events that provide the local population with health information and services.

Once the providers had identified at least three clients interested in receiving an IUD, the providers would give them an appointment for a future date. Additionally, they would request a project trainer to visit the health facility on that date.

\section{On-site supervised practice}

The second training phase consisted of certifying the trainees. To be certified, trainees were to conduct supervised insertions and removals with previously identified clients interested in receiving IUD services.

In the first phase, project personnel were trainers or supervisors based in Guatemala City, whereas in the second phase, we incorporated local trainers (often $\mathrm{MOH}$ providers) based in the same health area as the trainee; trainers who were not $\mathrm{MOH}$ employees were paid on a per-visit basis. However, trainers based in Guatemala City continued to supervise a large number of trainees. Using local trainers increased the cost-effectiveness of the training model, because salaries and transportation and per-diem costs decreased. Nonetheless, in several areas, finding experienced trainers able to conduct supervision visits proved difficult. Based on the project's limited experience, we recommend identifying local providers that had conducted at least 15 insertions or removals in the previous year and training them as local supervisors, whenever possible. Their training should include checking for adherence to the recommended insertion/removal and counseling techniques and supervising the use of clinical and counseling job-aids. 
In the first phase, trainees were advised to call project trainers at least two days in advance once a minimum of three clients had been identified and scheduled for IUD insertion. They were also told that up to three supervisory visits could be requested. In the second phase, the project's principal investigator decided that trainees should schedule five clients per visit and a maximum of two supervisory visits should be conducted. This change of scheme may have affected the number of providers that were certified. In both phases, supervisors conducted their training and supervision visits with the health district chief nurses to ensure that they would later be able to appropriately supervise IUD service provision. Project trainers advised chief nurses to conduct followup supervision of trainees one, two, and three months after certification.

During training visits, supervisors checked: 1) that insertion instruments and kits were sterilized, 2) that medical supplies were available and disinfected, 3) patient robes, 4) availability of sealed plastic bags for waste disposal, and 5) availability of four containers with decontamination and washing liquids. With the trainees, they reviewed data collection, informed consent, and counseling guidelines, as well as the clinical job aids. Having checked the materials and set up, the trainee counseled the client, obtained her consent, determined user eligibility, and provided the IUD service. Using a checklist, the trainers checked the quality of the insertion and removal services provided and then gave feedback to the trainee. If during pelvic examination any symptom of infection was detected, the client received a back-up method and was referred to a higher level of care for proper diagnosis and treatment of the infection (health posts rarely have medical supplies available to treat infection). At health centers with the capacity to treat such cases, the client received care immediately and was instructed to return for insertion when symptoms had disappeared - approximately two weeks later. The supervisor also checked that post-insertion information was complete and accurate, and that the data collection forms were properly filled out.

\section{Number of providers trained}

Table 2 shows the number of providers that started the two-day training and the practical training, and the number of providers certified at each participating health district.

In the first phase, of 52 enrolled trainees, two professional nurses and three nurse auxiliaries did not continue with practical training due to job rotation or personal and health reasons. Two more nurse auxiliaries began practical training but did not qualify for certification. Thus, $86 \%$ of all the providers enrolled were certified; the percentage of certified providers in each category (PNs, NACs, and NAPs) was also around 86\%. 
Table 2. Number of providers that started group training and practical training and number of providers certified, by project phase and health district

\begin{tabular}{|c|c|c|c|c|c|c|c|c|c|}
\hline \multirow{3}{*}{ Health Area } & \multicolumn{9}{|c|}{ Number of providers enrolled/certified } \\
\hline & \multicolumn{3}{|c|}{ Group Training } & \multicolumn{3}{|c|}{ Practical Training } & \multicolumn{3}{|c|}{ Certification } \\
\hline & PN & NAC & NAP & PN & NAC & NAP & PN & NAC & NAP \\
\hline \multicolumn{10}{|l|}{ First Phase (2003) } \\
\hline Chiquimula & 4 & 10 & 7 & 4 & 10 & 9 & 4 & 7 & 6 \\
\hline Escuintla & 6 & 11 & 0 & 6 & 11 & 0 & 4 & 10 & 0 \\
\hline Suchitepequez & 5 & 7 & 2 & 5 & 7 & 2 & 5 & 7 & 2 \\
\hline Subtotal & 15 & 28 & 9 & 15 & 28 & 11 & 13 & 24 & 8 \\
\hline \multirow[b]{2}{*}{ Second Phase (2004) } & \multicolumn{3}{|c|}{ Group Training } & \multicolumn{3}{|c|}{ Practical Training } & \multicolumn{3}{|c|}{ Certification } \\
\hline & PN & NAC & $\mathrm{MD}$ & PN & NAC & $\mathrm{MD}$ & PN & NAC & $\mathrm{MD}$ \\
\hline Chimaltenango & 5 & 14 & 1 & 0 & 9 & 1 & 0 & 3 & 0 \\
\hline Jalapa & 6 & 9 & 2 & 6 & 9 & 2 & 5 & 5 & 0 \\
\hline Jutiapa & 12 & 10 & 3 & 0 & 4 & 3 & 0 & 1 & 2 \\
\hline El Progreso & 7 & 7 & 0 & 6 & 8 & 0 & 5 & 7 & 0 \\
\hline Santa Rosa & 5 & 15 & 2 & 5 & 11 & 4 & 3 & 7 & 4 \\
\hline Solola & 3 & 11 & 2 & 0 & 4 & 3 & 0 & 1 & 2 \\
\hline Subtotal & 38 & 66 & 10 & 17 & 45 & 13 & 13 & 24 & 8 \\
\hline Total & 53 & 94 & & 32 & 73 & & 26 & 48 & \\
\hline
\end{tabular}

In the second phase, training concentrated in health centers, and physicians (including itinerant physicians who visited different health facilities every day as part of the coverage extension strategy) were invited to attend the training sessions. The data show poor completion rates: only about one-third of professional nurses and nurse auxiliaries that enrolled for the group training were certified, compared to eighty percent of medical doctors. Part of the problem seems to have been that several districts sent a large number of staff to attend group training without having a clear idea of the implicit commitment to conducting demand-identification activities or without intending to have all providers participate in the practical training and achieve certification. Districts in Chimaltenango, Jutiapa, and Solola, for example, sent 20 professional nurses but none of them even started theoretical training. Further, $81 \%$ of the professional nurses, $66 \%$ of the nurse auxiliaries, and $61 \%$ of the physicians started practical training and were certified. Several reasons might help explain this. The criteria for selecting health centers seemed not to have been followed. A review of the records shows that the area chiefs in Chimaltenango and Solola did not agree with demand-identification activities and instructed district chiefs to meet only spontaneous demand. In fact, several members of the new administration started relaying this message in August, and the new 2004-2008 MOH Basic Guidelines and Health Policies ${ }^{14}$ do not list contraception or family planning as a health program. The only reference - "meeting family planning demand" — is found in the section regarding services that should be provided to women of reproductive age as

\footnotetext{
${ }^{14}$ Ministerio de Salud. 2004. Lineamientos Básicos y Políticas de Salud. Año 2004-2008. Ministry of Health, Guatemala, October.
} 
part of the Maternal and Neonatal Program. Thus, areas where group training was conducted in August and September 2004 were strongly affected by these new directives. A second reason is that most supervisors conducted only one visit, instead of two or three as in the first phase. In several sites, this might have been due to the limited time left for practical training and because the vacations of health providers start in November.

\section{Improvement of quality of care}

An analysis of the checklists used to evaluate the quality of the services provided by trainees in the first phase showed that compliance with itemized procedures increased from 83 to 93 points between the first and the fifth observation. Nurse auxiliaries from health posts obtained the lowest average scores in the first observation (82 points), but in the fifth observation, they achieved the highest compliance (94 points) with itemized protocol procedures. Nurses and nurse auxiliaries from health centers increased their average scores from 83 to 93 points. In conclusion, "practice makes almost perfect" and the quality of the services provided increased with the practical training.

In the second phase of the project, the checklists showed perfect compliance with all itemized procedures on the checklist. This seems to have been the result of using all the job-aids that were introduced in this phase, such as the poster showing the 24 steps of the IUD insertion procedure, the checklist to determine eligibility and rule out pregnancy, and counseling materials.

\section{Duration of training}

The duration of individual practical training in the different areas ranged from one month in Chimaltenango to eight months in Suchitepéquez. The average duration of practical training in the first phase was 5.66 months (Chiquimula completed training in four months, Escuintla in 6, and Suchitepequez in 7), compared to 2.33 months in the second phase (Chimaltenango completed training in one month; Jutiapa, Sololá, and Santa Rosa in 2; El Progreso in 3; and Jalapa in 4). The shorter duration of training in the second phase seems to have been the result of the number of users needed to schedule a visit and the greater use of the jornada methodology, that is, organizing one-day events for service delivery at a health center. 


\section{Characteristics of trainees}

In the first phase, providers enrolled for group training completed a questionnaire on personal information. More than two-thirds were older than 30, married, and had two children or less. Nearly all married providers used contraceptive methods, even though 75\% were Catholic and 25\% were Protestant. Professional nurses were, on average, older than nurse auxiliaries. Compared to nurse auxiliaries from health centers, more professional nurses and nurse auxiliaries from health posts were married and also had larger families. Nurse auxiliaries from health centers were also more likely to be Protestant and to be using contraceptive methods than were their colleagues.

In the second phase, trainees did not fill out the form on personal data. Nonetheless, a diagnostic study was conducted and a large number of service providers were interviewed at the health centers. Of the 106 providers interviewed, 24 attended the training session (of these, 16 were subsequently certified and eight did not accomplish certification). Nearly two-thirds of the respondents were married. Of those selected for training, 92\% were non-indigenous (even though 16\% of those interviewed belonged to an indigenous group and thus, they were under-represented in the training). Of those who attended training sessions, 12 were professional nurses and 12 were nurse auxiliaries (whereas only 25 of the 106 respondents were professional nurses). Of those trained, 92\% met the requirement of having been employed at the $\mathrm{MOH}$ for at least a year, and nearly $70 \%$ had worked there for more than three years. Eighty-eight percent of those who were trained had received counseling and contraception in the previous 12 months. (In the previous year, FRONTIERS had extended nationwide a training program on the balanced counseling strategy, a method developed by an OR project.) Two-thirds of those who were trained said to have received IUD training, and 37\% said they had inserted at least one IUD. Two thirds reported that there was at least one provider trained in IUD services at their health centers, usually the physician. Lack of training or confidence was the main reason for not providing IUD services at the remaining health centers. About two-thirds of those that subsequently attended training were able to perform gynecological exams, collect Pap smears, or attend births, and all were able to suture wounds. All but one of these providers said they were willing to attend IUD training. The main reasons included a desire to learn, avoid turning away clients when the physician is away, provide better services, and acquire confidence to perform the required procedures. The provider who did not want to attend the training argued that she had an extremely heavy workload and did not agree with the method. Eighty percent of those who later attended training could not mention any negative effects from using the IUD, but all could list several advantages.

\subsection{Project Coordination and Supervision}

At project start-up, meetings were conducted with each health area director and with medical doctors and chief nurses from each district to present the proposed project activities, invite them to participate, and assess their support. If they decided to participate, roles and responsibilities would be defined. 
To ensure adequate supervision by project staff, we developed a comprehensive supervision guide, describing all aspects of IUD service provision, including balanced family planning counseling, IEC activities, installed capacity, provider technical competence, information system, and logistics. Project trainers and supervisors also used a 34-item observation checklist to assess IUD pre-insertion, insertion, and post-insertion service delivery behaviors. This checklist allowed them to assess the quality of the services provided by the trainee and helped the trainer identify those areas on which the trainee required feedback.

To strengthen supervision capabilities at the $\mathrm{MOH}$, we invited a staff member from the Reproductive Health Department to help teach each district course and to conduct on-site follow-up training visits. We also trained a large number of district chief nurses in IUD service delivery and in supervising activities using the various job-aids produced by the project. Chief nurses were instructed to observe IUD insertions and removals made by trainees one, two, and three months after certification.

To address concerns about the project's compliance with the Tiarht amendment and about the quality of services provided, we received three external supervision visits. A FRONTIERS consultant visited ten MOH health centers and posts in July 2003 to assess the quality of services provided by 15 nurses and nurse auxiliaries trained by the project. She concluded that IUDs were offered non-coercively as part of a range of methods for women to choose from, that the counseling provided was appropriate and complete, and that clients were appropriately screened. She also made recommendations to improve infection prevention procedures and trainee supervision. In October 2003, Dr Graciela Salvador, with the Catalyst Project, verified if services offered by the project promoted 3 to 5 years' optimal birth spacing and if women were offered a range of contraceptive options to achieve that end. The training model impressed her favorably. Dr. Orlando Urroz, from URC, assessed the quality of the counseling services and of informed consent procedures followed by trainees, and in November 2003, concluded that all quality requirements were met.

Some problems detected during routine supervision visits and the solutions implemented included:

- Several service delivery sites did not have autoclaves and often ran out of bleach. Providers often needed to buy chlorine solutions from local stores. Those solutions, however, come in different concentrations and, as noted by the supervisors, the providers did not know how to estimate the appropriate concentrations for disinfection. Since there were not enough non-sterile gloves, the trainees complained that they had to use sterile gloves unnecessarily. Thus, during on-site visits, training in infection prevention (which included adequate concentration of solutions) was reinforced. The project team also worked with $\mathrm{MOH}$ staff to include bleach in the procurement list and to better estimate when to restock non-sterile gloves. 
- Supervisors found that the use of the clinical checklists and instruments was not systematic. Thus, at each visit, they reinforced training in their use by discussing cases they had prepared before their visits.

- A large number of clients did not receive an IUD because the providers suspected the presence of an STI and we had not trained them to treat clients with cervical discharge or other symptoms. A protocol implemented at a later stage instructed nurse auxiliaries to provide such clients with an alternative contraceptive method and to refer them to a nurse or a physician.

- Occasionally, informed consent forms were not filled out correctly, and client data were incomplete and insufficient for analysis. The correct application of informed consent procedures was reinforced in the course of project implementation.

\section{RESULTS}

\subsection{Number of IUD Services Provided during Training}

Table 3 shows that 725 supervised IUD services (722 insertions and 3 removals) were provided as part of training activities. During the first phase, professional nurses provided 107 services, nurse auxiliaries at health centers provided 145 services, and nurse auxiliaries at health posts provided 49 services. During the second phase, medical doctors provided 60 supervised services, compared to 147 and 217 supervised services provided by nurses and nurse auxiliaries, respectively, at health posts. The health areas of Chiquimula, Santa Rosa, and El Progreso provided more than 120 supervised services; Escuintla and Jutiapa offered 95 services each; Suchitepequez provided 77 services; and Chimaltenango, Jutiapa, and Solola (the last areas to receive training and the most affected by the ambivalence of the new administration toward family planning services) provided less than 40 services each. 
Table 3. Number of IUD services provided during training, by type of provider, health area, and project phase

\begin{tabular}{|l|c|c|c|c|c|}
\hline \multirow{2}{*}{ Health Area } & \multicolumn{4}{|c|}{ Type of Provider } & \multirow{2}{*}{ TOTAL } \\
\cline { 2 - 5 } & Physicians & $\begin{array}{c}\text { Professional } \\
\text { Nurses }\end{array}$ & $\begin{array}{c}\text { Auxiliaries } \\
\text { at Center }\end{array}$ & $\begin{array}{c}\text { Auxiliaries } \\
\text { at Post }\end{array}$ & \\
\hline First Phase (2003) & & & 50 & 39 & 129 \\
\hline Chiquimula & & 40 & 58 & 0 & 95 \\
\hline Escuintla & 37 & 37 & 10 & 77 \\
\hline Suchitepequez & & 30 & 145 & 49 & 301 \\
\hline Subtotal & & 107 & & & \\
\hline Second Phase (2004) & 3 & 0 & 30 & & 33 \\
\hline Chimaltenango & 2 & 54 & 39 & & 95 \\
\hline Jalapa & 26 & 0 & 11 & & 37 \\
\hline Jutiapa & 0 & 56 & 65 & & 121 \\
\hline El Progreso & 29 & 30 & 67 & & 126 \\
\hline Santa Rosa & 0 & 7 & 5 & & 424 \\
\hline Solola & 60 & 147 & 217 & & \\
\hline Subtotal & 60 & 254 & 362 & 49 & 725 \\
\hline
\end{tabular}

Of the total number of supervised services in the second phase, 52 were offered by health agents that did not achieve certification within the framework of the project ( 7 by physicians, 8 by professional nurses, and 37 by nurse auxiliaries), and 372 were offered by providers that achieved certification ( 53 by physicians, 139 by nurse auxiliaries, and 180 by nurse auxiliaries). From the data in Tables 2 and 3, we can conclude that medical doctors who achieved certification provided an average of 6.6 services, compared to 10.7 and 7.5 supervised services provided by certified professional nurses and nurse auxiliaries, respectively. In the first phase, the average number of supervised services by certified providers was 8.2 for professional nurses, 6 for nurse auxiliaries at health centers, and 6.1 for nurse auxiliaries at health posts. Consequently, the training methodology used in the second phase yielded a larger number of service delivery opportunities for trainees.

Considering the number of insertions provided by service delivery agents that achieved certification, the number of agents certified, and the duration of practical training in participating health areas, we estimate that certified agents performed an average of 1.5 IUD services per month during training. The average varies considerably between areas, from 1.1 insertions per month/provider in Chiquimula and Escuintla, to 10.6 in Chimaltenango, to 6.2 in Jutiapa, and to 4.5 in Santa Rosa. In the other areas, the averages ranged from 1.1 to 3.3 insertions per month/provider. The total duration of the training was the main factor in this average. Thus, in phase-one areas, where training was conducted in approximately five months and 20 days, the averages were below 1.3 insertions per month/provider, whereas in phase-two areas, which conducted training in approximately 2 months and ten days, the lowest average was 2 insertions per month/provider. 


\section{Criteria used to rule out pregnancy}

An analysis of the clinical records of women who received an IUD in the second phase showed that in $31 \%$ of the cases the presence of menstruation had ruled out pregnancy. Current use of an injectable (35\%), exclusive breastfeeding in the first three months of an infant's life (26\%), absence of sexual relations since last menstruation (5.4\%), and birth within the last six weeks (2.1\%) were the other criteria used to rule out pregnancy before insertion.

\subsection{Screening and Contraindications}

In the first phase of the project, a record was kept for every woman requesting an IUD service, whereas in the second phase, records were kept only for those women that actually underwent an IUD insertion or removal. An analysis of first-phase records helped clarify the context surrounding demand for IUD services in Guatemala and explain the screening practices of providers.

During the first phase, 389 women requested an IUD from a service delivery agent trained by this project, but 88 women $(22.6 \%)$ were refused the method due to contraindications. In Chiquimula, only 77 out of 97 women who had requested an IUD received one (a 20.6\% rejection rate). In Suchitepequez, 129 out of 161 women interested in the method underwent an insertion (a 19.9\% rejection rate). In Escuintla, 95 out of 131 women interested in the IUD received one (a $27.5 \%$ rejection rate). The rejection rate in Escuintla is higher because of the high STI prevalence in the area. ${ }^{15}$

The most common contraindication for IUD use was vaginal discharge (leucorrhoea) identified during pelvic examination. Approximately 25\% of the women with contraindications had pelvic inflammation, and 13\% presented cervical stenosis. Escuintla, an area with a high STI prevalence, showed the highest percentage of women with vaginal discharge.

Assessing the total number of successful insertions proved not to be feasible. The reason was that clients were referred as needed to health centers or hospitals that were not participating in this project.

\footnotetext{
${ }^{15}$ A study conducted by the MOH National Reproductive Health Program in collaboration with the Health Sciences School of the Landivar University, with a sample of 667 sex workers, showed a 95\% prevalence of CIN I, II, and III and pelvic inflammatory disease, which are generally associated with HPV.
} 


\subsection{Follow-up, Failure and Complication Rates}

No lacerations or infections were recorded in the one-month follow-up clinical records. Only one pregnancy derived from expulsion was detected. The only complication recorded was one uterine perforation that was appropriately handled by the trainer. These rates are lower than the complication and failure rates observed in similar studies and for insertions conducted by physicians.

\subsection{Characteristics of IUD Clients}

According to the data collected in the client admission forms, about $48 \%$ of IUD users were between 20 and 29 years old, 9\% were under 20 and 3\% were over 40 . Nearly $70 \%$ of the women were prior contraceptive users. The preferred methods were injectables (34\%), the pill (13\%), lactational amenorrhea (12\%), the condom (6\%), and traditional methods (3\%). One-third of the women did not use any method previously. The areas with the highest proportion of contraceptive users who requested an IUD were El Progreso and Santa Rosa (above $80 \%$ ), mostly because $20 \%$ and $27 \%$, respectively, said they were using LAM, compared to $10 \%$ or less in most other areas. The areas with the lowest contraceptive prevalence were Sololá (42\%) and Chimaltenango (54\%).

In the second phase of the project, we used a new admission form that collected more data than the form used in the first phase. The data showed that $13 \%$ of the women that received IUD services in the six second-phase project areas had no schooling and that $52 \%$ had incomplete primary school (six years) education. Only $11 \%$ had a higher schooling level. The schooling levels of the partners were similar. Forty percent of the women had four children or more. Forty-six percent had a child less than one year of age and $48 \%$ had a child between one and five years of age. Fifty-six percent had traveled less than half an hour to visit the health center, and only 15\% had traveled more than an hour. Forty-two percent had walked to the health center and 51\% had used public transportation. Thirty-five percent did not spend money on transportation and 37\% spent less than five quetzales (about US \$0.65) to visit the health center. Ninety-three percent were not gainfully employed and thus, did not forego wages as a consequence of their visit to the health center; five percent spent less than US\$ 2.50. In the six second-phase areas, 75\% were prior contraceptive users. The preferred methods were Depoprovera (36.6\%), lactational amenorrhea (17.7\%), the pill (6.6\%), and the rhythm method or withdrawal (2.8\%). Twenty-three percent of all clients said they had never used a method. Of those who had, the most frequently mentioned were Depoprovera, the pill, and LAM. Forty percent of the women said they did not want any more children, and $90 \%$ of those that wanted more children preferred to space their next birth more than two years.

In conclusion, the project reached a large number of women who were not using contraception, were using ineffective methods, or would need a method soon (like LAM users). The women were young, poor, with large families, and with low schooling levels. 
Finally, nearly all of them were interested in using a contraceptive for more than two years, and 40\% apparently wanted to use an IUD instead of sterilization.

\subsection{Impact on IUD Service Provision}

The purpose of this project was to increase access to IUD services for women living in rural and semi-urban areas in Guatemala by increasing the number of trained providers. Table 4 presents data that were retrieved from the $\mathrm{MOH}$ Health Managerial Information System (SIGSA) to determine the long-term impact of the training activities conducted by the project.

In general, at first-phase health centers and posts, training seems to have improved access to IUD services. These services continued to be provided after the training, although not at higher levels than those observed before the intervention. The contribution to the total number of couple-years of protection (CYP) provided by participating health facilities ranged between 2 and 10\%. In second-phase areas, follow-up lasted only 2 to 4 months, because most service providers take vacations in late November and December. Yet, the average number of IUD services provided by participating health centers was higher than that in the pre-intervention period (considering as the pre-intervention period the early months of 2004 in second phase sites and the 12 months of 2003 in first phase sites). This increase is especially relevant given the extensive training in IUD services provided by Calidad en Salud in 2003. In second-phase areas, the percentage of CYPs provided by IUDs after training ranged between 10 and 50\% of the total CYPs provided, which suggests that the IUD has a stronger presence in the range of available methods, especially in El Progreso and Chimaltenango.

Considering all participating service delivery facilities, there is a clear upward trend in the delivery of all contraceptive services over time. Increased access to the IUD not only yields increased acceptance of IUDs, but also of other methods.

In conclusion, the project seems to have had a positive impact on the delivery of contraceptive services, particularly IUD services, at participating health centers and posts. 
Table 4. Average number of IUD insertions, couple-years of protection* (CYPs) provided by the IUD, and CYPs* provided by all temporary methods delivered by participating health centers and posts before, during and after training, by project phase and health area

\begin{tabular}{|c|c|c|c|c|c|}
\hline \multirow{3}{*}{$\begin{array}{l}\text { First-Phase } \\
\text { Health Areas }\end{array}$} & \multicolumn{5}{|c|}{ Year } \\
\hline & \multirow[t]{2}{*}{2002} & \multicolumn{3}{|c|}{2003} & \multirow[t]{2}{*}{2004} \\
\hline & & Before & During & After & \\
\hline \multicolumn{6}{|l|}{ Chiquimula } \\
\hline IUD insertions & 0.0 & 5.0 & 18.8 & 6.3 & 1.6 \\
\hline IUD CYPS & 0.0 & 17.5 & 65.8 & 22.0 & 5.6 \\
\hline Total CYPs & 555.8 & 283.1 & 449.4 & 690.1 & 242.0 \\
\hline Months & 12 & 2 & 4 & 6 & 12 \\
\hline \multicolumn{6}{|l|}{$\begin{array}{l}\text { Escuintla } \\
\text { Health Centers }\end{array}$} \\
\hline IUD insertions & 2.9 & 5.3 & 17 & 11.5 & 4.3 \\
\hline IUD CYPS & 10.15 & 18.4 & 59.5 & 40.25 & 15.05 \\
\hline Total CYPs & 122.5 & 336.9 & 367.4 & 339.5 & 417.3 \\
\hline Months & 12 & 4 & 6 & 2 & 12 \\
\hline \multicolumn{6}{|l|}{$\begin{array}{l}\text { Escuintla } \\
\text { Health Posts }\end{array}$} \\
\hline IUD insertions & 3.2 & 0 & 0.3 & 3.5 & 3.2 \\
\hline IUD CYPS & 11.2 & 0 & 1.05 & 12.25 & 11.2 \\
\hline Total CYPs & 79.4 & 91.4 & 77.4 & 91.9 & 102.0 \\
\hline Months & 12 & 4 & 6 & 2 & 12 \\
\hline \multicolumn{6}{|l|}{$\begin{array}{l}\text { Suchitepequez } \\
\text { Health Centers }\end{array}$} \\
\hline IUD insertions & 8.7 & 3 & 26.3 & 10.5 & 6.7 \\
\hline IUD CYPS & 30.3 & 10.5 & 92.0 & 36.8 & 23.3 \\
\hline Total CYPs & 378.7 & 428.0 & 474.0 & 334.1 & 432.9 \\
\hline Months & -12 & -3 & -7 & -2 & -12 \\
\hline \multicolumn{6}{|l|}{$\begin{array}{l}\text { Suchitepequez } \\
\text { Health Posts }\end{array}$} \\
\hline IUD insertions & 1.7 & 0 & 7.3 & 2 & 2.1 \\
\hline IUD CYPS & 5.95 & 0 & 25.55 & 7.0 & 7.35 \\
\hline Total CYPs & 115.6 & 83.5 & 168.8 & 70.7 & 170.9 \\
\hline Months & 12 & 3 & 7 & 2 & 12 \\
\hline
\end{tabular}

Source: Sistema de Información Gerencial en Salud (SIGSA). Form 6. 
Table 4 (Continued). Average number of IUD insertions, couple-years of protection* (CYPs) provided by the IUD, and CYPs* provided by all temporary methods delivered by participating health centers and posts before, during and after training, by project phase and health area

\begin{tabular}{|c|c|c|c|c|c|}
\hline \multirow[t]{3}{*}{$\begin{array}{l}\text { Second-Phase } \\
\text { Health Areas }\end{array}$} & \multicolumn{5}{|c|}{ Year } \\
\hline & \multirow{2}{*}{2002} & \multirow{2}{*}{2003} & \multicolumn{3}{|c|}{2004} \\
\hline & & & Before & During & After \\
\hline \multicolumn{6}{|l|}{ Chimaltenango } \\
\hline IUD insertions & 4.3 & 16.2 & 17.4 & 63.0 & 36.0 \\
\hline IUD CYPs & 15.1 & 56.7 & 61.1 & 220.5 & 126.0 \\
\hline Total CYPs & 59.5 & 239.0 & 309.1 & 326.9 & 381.6 \\
\hline Months & 12 & 12 & 9 & 1 & 2 \\
\hline \multicolumn{6}{|l|}{ Jalapa } \\
\hline IUD insertions & 0.2 & 4.1 & 4.0 & 15.8 & 6.0 \\
\hline IUD CYPs & 0.7 & 14.35 & 14.0 & 55.1 & 21.0 \\
\hline Total CYPs & 90.0 & 120.9 & 168.4 & 216.2 & 145.8 \\
\hline Months & 12 & 12 & 4 & 4 & 4 \\
\hline \multicolumn{6}{|l|}{ Jutiapa } \\
\hline IUD insertions & 13.2 & 7.9 & 5.5 & 17.5 & 3.0 \\
\hline IUD CYPs & 46.2 & 27.65 & 19.3 & 61.3 & 10.5 \\
\hline Total CYPs & 205.3 & 115.0 & 268.8 & 157.3 & 142.8 \\
\hline Months & 12 & 12 & 6 & 2 & 4 \\
\hline \multicolumn{6}{|l|}{ El Progreso } \\
\hline IUD insertions & 14.3 & 32.8 & 55.8 & 204.3 & 33.3 \\
\hline IUD CYPs & 50.05 & 114.8 & 195.3 & 715.2 & 116.4 \\
\hline Total CYPs & 169.8 & 554.3 & 737.5 & 1075.3 & 310.6 \\
\hline Months & 12 & 12 & 5 & 3 & 4 \\
\hline \multicolumn{6}{|l|}{ Santa Rosa } \\
\hline IUD insertions & 12.5 & 38.4 & 27.0 & 122.0 & 40.8 \\
\hline IUD CYPS & 43.75 & 134.4 & 94.5 & 427.0 & 142.6 \\
\hline Total CYPs & 344.2 & 542.1 & 317.1 & 501.7 & 312.8 \\
\hline Months & 12 & 12 & 6 & 2 & 4 \\
\hline \multicolumn{6}{|l|}{ Solola } \\
\hline IUD insertions & 1.1 & 2.7 & 0.5 & 6.5 & 3.5 \\
\hline IUD CYPS & 3.85 & 9.45 & 1.8 & 22.8 & 12.3 \\
\hline Total CYPs & 70.0 & 120.0 & 80.0 & 98.3 & 165.6 \\
\hline Months & 12 & 12 & 8 & 2 & 2 \\
\hline
\end{tabular}

Source: Sistema de Información Gerencial en Salud (SIGSA). Form 6.

CYPS: 15 pill cycles, 120 condoms, 4 Depoprovera injections, one new standard day method user or 4 new LAM users = each one CYP; 1 IUD $=3.5$ CYPS 


\subsection{Cost of Interventions}

In this section, we simulate the costs of scaling up the intervention for the $\mathrm{MOH}$ using data from this project. For this simulation, we will assume that the trainers/supervisors travel from Guatemala City to each health area and district, and we will use an average exchange rate of eight quetzales to 1 US dollar.

Table 5 presents the salary and benefits of MOH staff per month and per working day, as well as per-diem given to each type of health provider by the $\mathrm{MOH}$. To estimate the cost per working day, the monthly salary was divided between 17.08 , which is the average amount of workdays a month for MOH staff members (they work 22 days a month and have 45 vacation days and 14 holidays a year).

Table 5: Salaries and benefits, and per-diem of MOH staff by type of staff member, in US dollars

\begin{tabular}{|l|c|c|c|c|}
\hline \multirow{2}{*}{ Variable } & \multicolumn{3}{|c|}{ Type of staff member } \\
\cline { 2 - 5 } & Physician & Nurse & $\begin{array}{c}\text { Auxiliary } \\
\text { Nurse }\end{array}$ & Driver \\
\hline Monthly salary and benefits & 906 & 383 & 344 & 269 \\
\hline $\begin{array}{l}\text { Salary and benefits per } \\
\text { working day }\end{array}$ & 53.05 & 22.42 & 20.13 & 15.73 \\
\hline $\begin{array}{c}\text { Total per-diem per day } \\
-\quad \text { Meals }\end{array}$ & 10 & 20 & 15 & 10 \\
$-\quad$ Hotel & 10 & 10 & 7.5 & 5.0 \\
& & 10 & 7.5 & 5.0 \\
\hline
\end{tabular}

Travel expenses for trainers and supervisors account for a large proportion of the costs, aside from salary and benefits for staff time used in training activities. The MOH bought several 2003 Mazda double-cabin pickup trucks at US \$ 20,750. The MOH depreciates vehicles at 20\% per year for the first year and 15\% in subsequent years. The cost of the vehicle would therefore decrease \$4,150 in the first year and \$3,112.5 in the second year. Averaging these costs and allowing for 220 working days per year, the cost of the vehicle is $\$ 16.5$ per day. In addition, the MOH spends an average of US \$750 on vehicle maintenance per vehicle per year, or US \$3.4 per day, so the total cost of a vehicle is $\$ 19.90$ per day.

Finally, the average cost of gasoline per liter in 2003 was \$ 0.63, and considering an average of six kilometers per liter for this type of vehicle, the cost of gasoline was $\$ 0.105$ per kilometer. 


\section{Two-Day Courses}

Table 6 presents the itemized costs of each two-day course. These costs can be summarized in three categories: salary for time used by the MOH staff members in the courses, travel and per-diem expenditures, and other direct costs. The total cost per course was estimated at US\$2,865 or \$ US143.25 per participant.

Each two-day course required ten physicians/days to conduct training activities: four to teach the course and six to prepare it and coordinate activities, including a visit to the health area and to each participating health district to discuss training with area and district chiefs. (In future efforts, health area staff could coordinate activities with health districts and collect their basic data, so that these visits could be eliminated). In addition, the chief area nurse devoted three days to coordinate local activities and administration, and one driver devoted six days to drive the trainers and supervisors to the districts and to the health area.

Table 6: Itemized costs per each two-day group training course in US dollars.

\begin{tabular}{|c|c|}
\hline LINE ITEM & US \$ \\
\hline \multicolumn{2}{|l|}{ SALARY AND BENEFITS OF STAFF (STAFF TIME) } \\
\hline $\begin{array}{l}10 \text { physician days to prepare activities and teach at course @ } \$ 53.05 \\
\text { per day }\end{array}$ & 530 \\
\hline 3 nurse days to prepare activities @ \$22.42 per day & 67 \\
\hline 12 nurse auxiliaries $X 2$ days $X \$ 20.13$ & 483 \\
\hline 7 nurses $X 2$ days $X \$ 22.42$ per day & 314 \\
\hline 1 physician $X 2$ days $X \$ 53.05$ per day & 106 \\
\hline 1 Driver $\times 6$ days $\times 15.73$ & 94 \\
\hline Sub-total & 1,594 \\
\hline \multicolumn{2}{|l|}{ TRAVEL AND PERDIEM } \\
\hline 10 physician days $\times \$ 20$ & 200 \\
\hline 12 nurse auxiliaries $X 2$ days $X \$ 15$ & 360 \\
\hline 7 nurses $X 2$ days $X \$ 15$ per day & 210 \\
\hline 1 physician $X 2$ days $X \$ 20$ per day & 40 \\
\hline 1 driver $\times 6$ days $\times \$ 10$ & 60 \\
\hline Vehicle: 6 days $\times \$ 19.90$ & 119 \\
\hline Fuel: 300 kms X \$ 0.105 & 31 \\
\hline Sub-total & 1,020 \\
\hline \multicolumn{2}{|l|}{ OTHER EXPENSES } \\
\hline IEC MATERIALS: 20 participants X \$12.56 & 251 \\
\hline TOTAL & 2,865 \\
\hline
\end{tabular}

Twenty participants attended each two-day course. Using the information on Table 1, we estimate that on average there were 7 nurses, 12 nurse auxiliaries and one physician in each course. In addition to salaries and benefits for these 40 staff days, we need to 
include their per-diem and travel expenses (US\$ 3 per participant to go from the districts to the health area and back). In addition, we need to account for the travel and per-diem expenses of the trainers, supervisors and the driver, including use of the car for six days and fuel for 300 kilometers on average.

The project spent an average of \$ 12.56 per participant on training materials, or \$ 251.25 per course. The materials included the IUD Service Delivery Manual, the Promotion Manual, forms to determine eligibility and to rule out pregnancy, and all other clinical forms.

\section{On-Site Training and Supervision}

Table 7 shows that the total costs of applied training were $\$ 35,282$, or approximately $\$ 392$ per provider trained.

The basic categories to estimate the costs of on-site training and supervision visits are: the salary and per-diem of trainers and trainees for time devoted to the activity; the travel and per-diem costs of trainers to the service delivery units; and the costs of providing the service. In what follows, we estimate that trainers devoted one day per visit, and that trainees devoted 0.60 days per visit.

Trainers devoted a total of 1.4 visits to the six nurses, 28 nurse auxiliaries and five physicians who did not complete the applied training. In contrast, they made a mean of 1.8 visits to the 26 nurses, 56 nurse auxiliaries, and 8 physicians who did complete the applied training and were certified.

The direct travel and per-diem costs include per-diem for 217 physician days, 217 driver days, 217 days in which the car was used, and fuel for an average of 50 kilometers per visit.

Other expenses include the IEC materials used for promoting services and \$3.11 for the materials used for providing the IUD services. These include the TCU 380 A $(\$ 1.80)$, water and soap (\$0.67), disinfectant (\$0.18), gauze (\$0.16), disposable gloves $(\$ 0.16)$ and chlorine solution (\$0.15). Although ideally we should also include the cost of the use of the health center and post-clinical infrastructure, given the number of services provided

we estimate that this cost would be minimal and would not substantially affect the total costs.

\section{Total costs}

Based on the above analysis, the total cost of the intervention for the MOH would be US\$ 38,147 , US $\$ 424$ per certified provider or $\$ 50$ per IUD provided during training activities (\$14.28 per couple year of protection). 
Table 7: Itemized costs of on-site training and supervision. US dollars.

\begin{tabular}{|c|c|}
\hline LINE ITEM & US \$ \\
\hline \multicolumn{2}{|l|}{ SALARY AND BENEFITS OF STAFF (STAFF TIME) } \\
\hline 6 nurses $X 1.4$ visits $X 0.6$ days per visit $X \$ 22.42$ per day & 113 \\
\hline 28 nurse auxiliaries $X 1.4$ visits $X 0.6$ days per visit $X \$ 20.13$ & 473 \\
\hline 5 physicians $X 1.4$ visits $X 0.6$ days $X \$ 53.05$ per day & 94 \\
\hline 26 nurses $X 1.8$ visits $X 0.6$ days per visit $X \$ 22.42$ per day & 1,490 \\
\hline 56 nurse auxiliaries $X 1.8$ visits $X 0.6$ days per visit $X \$ 20.13$ & 1,356 \\
\hline 8 physicians $X 1.8$ visits $\times 0.6$ days $X \$ 53.05$ per day & 458 \\
\hline Trainers time: 1.4 visits $\times 39$ trainees $\times 1$ day $\times \$ 53.05$ & 2,897 \\
\hline Trainers time: 1.8 visits $X 90$ providers $X 1$ day $X \$ 53.05$ & 8,594 \\
\hline 1 Driver $X 217$ days $X 15.73$ & 3,413 \\
\hline Sub-total & 18,888 \\
\hline \multicolumn{2}{|l|}{ TRAVEL AND PERDIEM } \\
\hline 217 physician days $X \$ 20$ & 4,340 \\
\hline 217 driver days $X \$ 10$ & 2,170 \\
\hline 217 vehicle days $X \$ 19.90$ & 4,318 \\
\hline Fuel: 217 visits $X 50 \mathrm{kms} \times \$ 0.105$ & 1,139 \\
\hline Sub-total & 11,967 \\
\hline \multicolumn{2}{|l|}{ OTHER EXPENSES } \\
\hline $\begin{array}{l}\text { IEC Materials (design and printing of 100,000 leaflets, } 2,500 \text { posters, and } \\
150 \text { insertion and removal posters). }\end{array}$ & 2,172 \\
\hline 725 insertions $X \$ 3.11$ in materials & 2,255 \\
\hline Sub-total & 4,427 \\
\hline TOTAL & 35,282 \\
\hline
\end{tabular}

\section{DISSEMINATION AND USE OF RESULTS}

The results of this project were presented at an expert meeting in Southampton, England, and the project was used as a model to conduct similar projects in Africa and Asia, as part of the activities of the Frontiers in Reproductive Health Program, the Southampton University's Opportunities and Choices Program, and FHI in Kenya. Presentations were also made at the APHA 2004 Annual Meeting and at the Regional Medical Congress in Suchitepequez during a session entitled "New Family Planning Service Delivery Strategies."

This project was implemented with the collaboration of $\mathrm{MOH}$ authorities. The staff of the Reproductive Health Department participated in training and supervision activities, and the director of the department was periodically informed of activities and results. In January 2004, a new presidential administration was inaugurated in Guatemala, and the project's activities and preliminary results were presented in March to the new reproductive health authorities. Although the new authorities have not been as supportive 
of IUD expansion activities, close communication with national, area, and district chiefs has allowed health facilities to improve IUD provision in Guatemala. We have also worked closely with the Calidad en Salud project, the USAID-funded bilateral project that conducts most family planning training activities in Guatemala. Calidad en Salud will continue to use our training strategy to increase IUD access, an important goal especially in view of the current reliance on DepoProvera, an expensive method, and of USAID’s plans to stop donating contraceptives to Guatemala in the near future.

Some materials developed by this project have been adopted by other international organizations. For example, FHI reproduced in Nicaragua the posters on the 24 IUD insertion steps and the 16 IUD removal steps, and EngenderHealth has requested permission to adapt this material to use it around the world. We also shared these materials with other IUD projects at the Southampton meeting and some have been adapted for use in Uganda. EngenderHealth and the Honduran $\mathrm{MOH}$ are adapting the materials for use in an OR project that will test the impact of information activities on IUD demand.

In the following months, APROVIME and FRONTIERS staff in Guatemala will continue to disseminate the results of this project. Presentations will be made to nursing schools, health area chiefs and nurse chiefs in non-participating areas, and other NGOs. A meeting will be conducted to present the results to other reproductive health service delivery organizations and international donors. The final report will be distributed among donors interested in Guatemala, such as USAID, UNFPA, the Inter-American Development Bank, the World Bank, as well as cooperating agencies and organizations, such as FHI, URC, JHPIEGO, among others in the country. We will also disseminate the results to the IUD subcommittee of the International Best Practices (IBP) group. Finally, FRONTIERS will disseminate the results worldwide. 


\section{CONCLUSIONS AND RECOMMENDATIONS}

This study has shown that non-professional health providers can effectively provide quality IUD services in Guatemala. This finding confirms the experiences of other countries, including Honduras, Peru, and Kenya. Only one perforation and one pregnancy were detected during the implementation of the strategy and both were handled correctly. No cervical lacerations, infections, or post-insertion infections were identified. The estimated expulsion rate (one in 411 services provided by nurse auxiliaries) is remarkably lower than that observed in previous studies and well within acceptable ranges for professional personnel. Counseling was provided in a balanced manner without emphasizing or promoting the IUD.

In terms of the training strategy followed, we observed that a large number of trainees were able to complete the training and that, unlike what has been observed with other training strategies, almost all nurse auxiliaries trained on-site continued to provide IUD services after completing the training. Thus, even though the model might be somewhat more costly than that used at high-productivity centers, the strategy is probably more cost-effective because trained providers continued to use their newly acquired skills. To improve the cost-effectiveness of the strategy, the $\mathrm{MOH}$ should use as trainers those providers in a health area that are most experienced in providing IUD services. This would represent substantial savings in time and travel expenses.

The results support the idea that training nurse auxiliaries will increase the use of IUD services in Guatemala. Given the strong reliance of the family planning program on DepoProvera, the high cost of this method and USAID's plans to phase out the donation of contraceptives in the near future, the $\mathrm{MOH}$ should seriously consider supporting the scaling up of this strategy and extending the range of contraceptive choices available to women in rural and semi-urban areas. In this project, we observed that women clearly understand the long-term advantages of the IUD and anecdotal evidence shows that many women that had thought, but were not absolutely sure, about undergoing sterilization preferred the IUD to a permanent method.

The success of this strategy was due to careful training —in class and in-service- and close follow-up, collaboration with district level workers and MOH officials, well designed training materials, and adequate supervision. Many trainer hours were invested to guarantee that each participant would follow established procedures. To extend IUD training nationwide, it is necessary to maintain these high training and supervision standards.

The strategy is not problem-free. During project implementation, we had to work very closely with $\mathrm{MOH}$ officials to ensure that health centers and posts had adequate supplies to provide the service with quality. The strategy requires that such a procurement level remain in place beyond the life of this project.

Although project participants were carefully selected, we recommend that only personnel with interest, motivation, and basic skills be trained to provide IUD services. Training 
personnel who will not offer the method to ever-increasing user populations represents a waste of time and money. Future extension activities should select personnel with a strong background in contraceptive technology and experience in Pap smears and gynecological examinations. Area chiefs often insisted on extending the training to all staff members in the health districts, even if many were not interested in it and did not plan to use the skills they would acquire. Frequently, area and district chiefs requested the training but did not support follow up information activities, so practical training could not be conducted due to a lack of clients. Every effort should be made to persuade area and district chiefs to use existing resources as wisely as possible. If the goal is to help all health providers learn about the advantages and characteristics of the IUD, shorter courses can be designed to achieve this end. Managers should understand that a constant flow of clients is needed to acquire and maintain skills, and thus, if the requirement of carrying out community information activities during and after training is not met, their already scarce resources will be wasted.

Drawing from the project's experience, we recommend using a peer-training strategy whereby fellow auxiliaries review and rehearse each step of the IUD case management procedures. This strategy proved particularly useful and, if made affordable, it can be adapted for national scaling-up.

Finally, we recommend that district nurses and physicians continue to use the supervision checklists developed by the project. With this job-aid, supervisors can provide specific feedback to maintain an appropriate skill level. 